\title{
SERVICIOS SOCIALES EN LA COMUNITAT VALENCIANA: EL ACTUAL 'MODELO VALENCIANO' Y UNA NUEVA AGENDA DE CONSTRUCCIÓN DE UN MODELO DERECHOS SOCIALES
}

\author{
Social Services in the region of Valencia: the current 'valencian model' and \\ a new set of ideas for the construction of a model of social rights
}

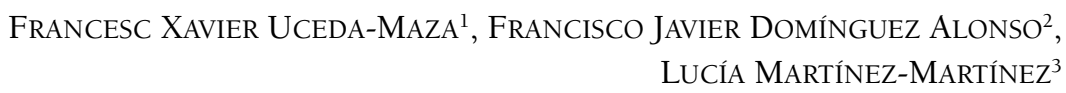

Resumen

Introducción: La aprobación de la LRSAL* presenta un panorama de cambio para los Sistemas de Servicios Sociales de España, sobre todo en lo atingente a lo local. Un grupo de expertos/as de la Comunitat Valenciana ha trabajado esta circunstancia como una oportunidad positiva.

Material y Métodos: Mediante el análisis documental y el debate de la realidad del sector realizado por este grupo de expertos/as, se ha desgranado el modelo actual de los servicios sociales municipales valencianos, se ha reflexionado en sus diferencias con los modelos basados en leyes de tercera generación, y a partir de ello, se atreve a proponer las bases para la construcción de un nuevo modelo del Sistema Valenciano de Servicios Sociales.

Resultados: Los resultados nos han llevado a indicar que el modelo actual de los servicios sociales valencianos se caracteriza por haberse desarrollado de forma centralizada, desordenada, con escasa calidad y al margen del territorio. La comparativa en legislación nos indica que no se asienta sobre derechos subjetivos, tiene desestructurados e invisibilizados sus recursos, y sobre todo carece por completo de planificación en todos los ámbitos del sistema, siendo especialmente grave en el ámbito de la organización funcional y territorial.

Discusión y conclusiones: El nuevo modelo se debe asentar en la planificación estratégica, la proximidad, la prevención, la calidad, la colaboración de y entre todos sus actores, y sobre todo en la primacía de las personas sobre el sistema.

Palabras clave: Servicios Sociales, proximidad, planificación estratégica, leyes de tercera generación, derecho subjetivo, Trabajo Social.

* Ley 27/2013, de Racionalización y Sostenibilidad de la Administración Local
Abstract

Introduction: The endorsement of the LRSAL ${ }^{* *}$ presents an environment of change for the social services systems in Spain, especially at the local level. A group of experts in the region of Valencia (Comunitat Valenciana) have found in this situation a positive opportunity to bring about change.

Material and Methods: Through documentary analysis and discussion of the reality of the sector carried out by this group of experts, the current model of the Valencian municipal social services has been divided into sections, and a reflection has been carried out taking into account models based on third-generation rights. From that perspective, the group of experts are in a position to propose the basis for the construction of a new model of the Valencian social services system.

Results: The results have led us to suggest that the current model of the Valencian social services is characterized by having a centralized, disorganized and poor quality structure which is outside the territory. The comparison with the legislation indicates that it is not based on subjective rights, as resources are badly structured and above all, there is a lack of planning in all the stages of the system, which is especially serious in the scope of the functional and territorial organization.

Discussions and conclusions: The new model should be based on strategic planning, proximity, prevention, quality, and collaboration between all participants, and especially in the primacy of the people over the system.

Keywords: Social Services, proximity, strategic planning, third-generation rights, individual right, Social Work.

\footnotetext{
** Law 27/2013, Rationalization and Sustainability of Local Administration in Spain
}

1. Universitat de València. Departament de Treball Social i Serveis Socials. Avgda. Tarongers n. ${ }^{\circ}$ 4-B. 46071 València. Tel: 963828835. Francesc.Uceda@uv.es

Institución de apoyo a la investigación: Universitat de València. Instituto Interuniversitario de Desarrollo Local (IIDL). Programa de ayudas de investigación para acciones especiales de la UV. Precompetitivo. (UV-INV-PRECOMP12-82190).

2. Universitat d'Alacant. Departament de Treball Social i Serveis Socials

3. Universitat de València. Departament de Treball Social i Serveis Socials 


\section{Introducción}

«El sistema de los Servicios Sociales se ha desarrollado intensamente en los últimos 30 años adquiriendo la identidad suficiente para ser reconocido como un instrumento fundamental de nuestro Estado del Bienestar, constituyendo uno de sus pilares»(Uceda, 2011: 237). Este sistema moderno de Servicios Sociales nace con la aprobación de La Constitución (1978), y la asunción de competencias en materia de «asistencia social» por las Comunidades Autónomas $^{4}$ (art. 148.1.20. ${ }^{a}$ de la Constitución Española) ${ }^{5}$. A partir de 1982 las comunidades autónomas legislan como materia propia, habiéndose desarrollado 17 sistemas diferentes de Servicios Sociales (Vilà, 2012).

Cuando las CC.AA asumen las transferencias realizadas desde la Administración General del Estado, se encuentran con la necesidad de ordenar y regular los bienes y obligaciones recibidos, pero también con expandir, modernizar y democratizar la acción social, ya que es un ámbito donde marcar la impronta política y trascender a la ciudadanía.

Desde 1982 y hasta 1992 nacen las leyes de primera generación en servicios sociales que «tienen la virtud de conseguir institucionalizar un nuevo sistema de protección social» (Santos, 2012: 106). Con ellas «se busca diseñar un sistema claramente diferenciado de la herencia benéfico-asistencial propia del periodo franquista» (Carbonero y Caro, 2013: 123).

Este nuevo sistema asienta sus bases en el ámbito local, por la tradición existente en el Estado Español desde las leyes de beneficencia de dotar a las administraciones locales (grandes ayuntamientos y diputaciones) de estructuras de asistencia social (Hospitales, Orfanatos, Asilos, etc.) ${ }^{6}$. La Ley 7/85 de Bases de Régimen Local, normaliza está tradición y reconoce la obligación de las Administraciones Locales, de prestar Servicios Sociales, al asignar en su artículo 26.1.c, la competencia en materia de Servicios Sociales a los municipios de más de 20.000 habitantes, y a las Diputaciones provinciales les otorga el papel de ayudar a los municipios de menos habitantes para la implantación y mantenimiento de los Servicios Sociales en todo el territorio nacional.

4. A partir de ahora, CC.AA.

5. El Estado no considera este tema competencia suya y aunque hace intentos por legislar en la materia, de hecho se elabora un borrador de ley, algunas CC.AA rechazan esta posibilidad, de acuerdo con este artículo 148, y a su vez son las que van introduciendo en sus Estatutos la competencia exclusiva en materia de Asistencia Social. (Ley Orgánica 5/1982 de 1 de julio del Estatuto de Autonomía de la Comunitat Valenciana, artículo 31, apartado 24).

6. Es el único sistema donde la administración local ejerce amplías competencias desde la primera Ley de Beneficencia de 1822. (Uceda, 2011). 
Ante el déficit de una norma estatal que unifique unos servicios mínimos en todo el Estado, en 1987 se aprueba el Plan Concertado de Prestaciones Básicas en Servicios Sociales en Corporaciones Locales ${ }^{7}$, con la finalidad de establecer unos mínimos comunes en todos los municipios y subvencionar parte de la inversión inicial necesaria para la implantación de los servicios sociales, aunque «no era un instrumento de financiación incondicional de la Administración Local» (Carbonero y Caro, 2013: 125).

A partir de 1993 se inicia un proceso de revisión de las leyes de servicios sociales vigentes en las CC.AA, denominado por Vilà «segundas leyes» (2012: 144), o leyes de segunda generación. Para el autor no aportan nada nuevo o substantivo a las anteriores, solo buscan la extensión y consolidación del sistema, y en algunos casos, solo dejar la impronta política del nuevo partido que asciende al poder.

Es en el año 2006, con la aprobación de la Ley de Promoción de la Autonomía Personal y Atención a la Dependencia ${ }^{8}$, que introduce un sistema garantista (derecho subjetivo y Catálogo de recursos), cuando se inicia una revolución legislativa en Servicios Sociales y aparecen las Leyes de Tercera Generación. Según Casado y Fantova la LPAPAD constituye «un primer paso hacia la protección jurisdiccional del derecho a los servicios sociales, en los que incide directamente, y a partir de la que cabe esperar la consolidación futura del cuarto pilar del Estado de bienestar» (2007: 145).

Ante el hito de la aprobación de la LPAPAD, se realizaron esfuerzos metodológicos desde el ámbito técnico para apoyar en el proceso de creación de las nuevas leyes, y que éstas recogieran las últimas innovaciones conceptuales y organizativas reivindicadas por los y las profesionales de servicios sociales. A destacar el documento realizado desde la Asociación Directoras y Gerentes de Servicios Sociales titulado Las nuevas Leyes de Servicios Sociales. Criterios para valorar su elaboración o sus contenidos (García, 2007), que aspiraba a que en el conjunto de las nuevas leyes hubiera una unidad conceptual y metodológica.

Para Aguilar (2013) el sistema se halla en crisis, siendo anterior a la actual crisis económica, al postular las leyes un sistema que no coincide con lo que realmente se realiza, y que habitualmente no se cumple, truncando los anhelos de la ciudadanía y de las y los profesionales.

A esta debilidad estructural del sistema hay que añadir en estos momentos lo que ha supuesto la actual crisis financiero/económica, y los Programas Nacionales de Reforma y de control del déficit aplicados por las administraciones

7. A partir de ahora $\mathrm{PCPB}$

8. A partir de ahora LPAPAD

Alternativas. Cuadernos de Trabajo Social, 22, 2015, pp. 93-121 - ISSN 1133-0473 DOI: 10.14198/ALTERN2015.22.06 
que ha llevado a recortar en unos casos y suprimir en otros, servicios públicos, entre ellos los que se prestaban desde la LPAPAD y el PCPB. El Plan Nacional de Reformas enviado a Bruselas recoge que con la aplicación de la LRSAL y la supresión de Servicios Sociales en los Ayuntamientos, se ahorraran 3.282 millones, casi la totalidad de lo que invierten con fondos propios las Corporaciones Locales en ellos en el conjunto de España ${ }^{9}$.

Por otra parte, la Ley 27/2013, de 27 de diciembre, de racionalización y sostenibilidad de la Administración Local (LRSAL) supone una modificación muy importante en las atribuciones de los Ayuntamientos en todas sus áreas de intervención competencial. Está aprobada y vigente, pero existen diferentes interpretaciones para poder aplicarla en distintos sentidos, sobre todo en el ámbito de los Ss.Ss. También habrá que esperar el resultado de los recursos acerca de su legalidad ya que se considera que vulnera, desde distintas perspectivas, la autonomía local ${ }^{10}$.

La LRSAL dice en el art. 25 2.e) que los municipios ejercerán como competencia propia sólo la «Evaluación e información de situaciones de necesidad social y la atención inmediata a las personas en situación o riesgo de exclusión social», y en el art. 26 se determinan que sólo en los municipios con población superior a 20.000 habitantes.

Las Diputaciones asumirán esta competencia en Ayuntamientos con menos de 20.000 habitantes. También podrán solicitarlo así los Ayuntamientos de más de 20.000 habitantes. Las Diputaciones podrán elegir la forma de gestión que mejor garantice el cumplimiento de los principios de eficiencia y sostenibilidad, por lo que se abre la puerta a la privatización.

Por otra parte, la competencia en materia de «Prestación de los servicios sociales» se atribuye a la Administración Autonómica, pudiendo ésta delegar en los municipios pero siguiendo criterios homogéneos y asumiendo la C.A el $100 \%$ de la financiación necesaria.

Según la Disposición Transitoria Segunda (asunción por las CC.AA de las competencias relativas a Ss.Ss) se indica: a) Las Comunidades Autónomas a

9. La financiación de los servicios sociales se distribuyen de la siguiente forma: $2.119 \mathrm{mi}-$ llones la Administración General del Estado, de los que transfiere a las Comunidades Autónomas 1.404; las Comunidades Autónomas 9.793 millones de los que transfieren a las Entidades Locales 1.452 y finalmente éstas de sus recursos propios 3.821 millones. En aplicación de la LRSAL las Entidades Locales deberán dejar de invertir en sus Servicios Sociales una buena parte de los fondos que venían invirtiendo hasta el momento. Datos de la Asociación Estatal de Directoras y Gerentes de Servicios Sociales.Índice DEC 2013.

10. Se han presentado 9 recursos de inconstitucionalidad, admitidos a trámite por el Tribunal Constitucional. 
31 de diciembre de 2015 asumen la titularidad de los Ss. Ss.; b) Previa elaboración de un plan para la evaluación, reestructuración e implantación de los servicios, las CC.AA. en el ámbito de sus competencias, habrán de asumir la cobertura inmediata de dicha prestación; c) La gestión de las CC.AA. no podrá suponer un mayor gasto para el conjunto de las Administraciones Públicas; d) Sin perjuicio de la posibilidad de las CC.AA. de delegar dichas competencias en los municipios o diputaciones provinciales y e) Si no los asumen y no los delegan, los servicios seguirán prestándose por los municipios con cargo a la comunidad autónoma.

La Ley 5/1989, de 6 de julio, de Servicios Sociales de la Comunitat Valenciana ${ }^{11}$ es la primera Ley de la C.V., similar a todas las de primera generación. En el año 1997 se aprueba la segunda ley de servicios sociales (Ley 5/97), que pertenecería al grupo de las «segundas leyes», que prácticamente no ha sido desarrollada ${ }^{12}$. En los años siguientes el Consell inicia una etapa de aprobación de normativas que, lejos de armonizar el sistema, lo fragmentan y diluyen, incluso contradicen a la Ley 5/97 (Uceda, Pitarch, Pérez-Cosín y Rosaleny, 2012).

Ante este escenario confuso y el contexto de cambio en el que estamos inmersos en estos años, el presente artículo realiza un diagnóstico de los elementos substantivos de los Servicios Sociales en la C.V., una comparación con la legislación de otras CC.AA y la formulación de unas propuestas para una nueva Ley de Servicios Sociales.

\section{Material y métodos}

Los resultados que aquí se muestran forman parte de un proyecto de investigación mayor realizado en el Instituto Interuniversitario de Desarrollo Local de la Universitat de València. Su finalidad ha sido aplicada, y su objetivo ofrecer un análisis de la situación y generar propuestas para una nueva articulación a los actores políticos, sociales y profesionales.

Específicamente en este artículo se muestran parte de los resultados del análisis del 'Modelo Valenciano'13 de Servicios Sociales, a partir de la situación

11. En adelante C.V.

12. Preveía el desarrollo de planes que aclaraban el sistema y especialmente el papel de los ayuntamientos como: Plan Concertado de Servicios Sociales, Plan General de Ordenación, Plan de Financiación de las Entidades Locales, Convenios plurianuales con las entidades locales que no se han desarrollado. (Belis y Moreno, 2002).

13. Entrecomillamos la expresión 'modelo valenciano' ya que en realidad no se puede considerar un modelo digno a seguir. 
actual y de las necesidades reales detectadas por los/as técnicos/as del sistema y se proponen las bases para la construcción de un nuevo sistema de Servicios Sociales en la C.V.

Se han utilizado dos técnicas de investigación dentro de una estrategia cualitativa: a) Panel de expertos y b) Análisis documental. El panel de expertos, se constituyó en la investigación, a partir de informantes clave, que por su trabajo, vinculación al sistema y conocimiento profundo desde distintos ámbitos del sistema podían realizar un análisis cualitativo del modelo valenciano y formular los presupuestos sobre los que se debía articular una nueva etapa en el sistema. Junto a los expertos que figuran en la Tabla 1, asistieron en calidad de observadores tres miembros del equipo de investigación ${ }^{14}$, que introdujeron preguntas, solicitaron aclaraciones y registraron los debates.

Tabla 1. Panel de Expertos de Servicios Sociales

\begin{tabular}{|l|l|l|c|l|}
\hline Experta/o & Profesión & Ámbito de Trabajo & $\begin{array}{c}\text { Años de } \\
\text { trabajo en } \\
\text { el sistema }\end{array}$ & $\begin{array}{c}\text { Vinculado } \\
\text { actualmente }\end{array}$ \\
\hline PAA & $\begin{array}{l}\text { Trabajador } \\
\text { Social }\end{array}$ & Diputación de València & 25 & $\mathrm{Si}$ \\
\hline MGA & Psicólogo & Conselleria Bienestar Social & 30 & $\mathrm{Si}$ \\
\hline MML & $\begin{array}{l}\text { Trabajadora } \\
\text { Social }\end{array}$ & $\begin{array}{l}\text { Servicios Sociales Municipales- } \\
\text { Ayuntamiento menor 10.000 hab }\end{array}$ & 23 & Si \\
\hline AMV & $\begin{array}{l}\text { Trabajadora } \\
\text { Social }\end{array}$ & Conselleria Bienestar Social & 37 & $\begin{array}{l}\text { No (jubilada } \\
\text { hace 2 años) }\end{array}$ \\
\hline JRP & Psicólogo & $\begin{array}{l}\text { Servicios Sociales Municipales- } \\
\text { Ayuntamiento más 40.000 hab }\end{array}$ & 29 & Si \\
\hline JESM & Psicólogo & Conselleria Bienestar Social & 23 & Si \\
\hline XSM & $\begin{array}{l}\text { Trabajadora } \\
\text { Social }\end{array}$ & Conselleria Bienestar Social & 22 & Si \\
\hline
\end{tabular}

Fuente: Elaboración Propia

Este panel de expertos/as debatió de forma conjunta durante cuatro encuentros, dos se dedicaron al diagnóstico; el primero a establecer los ejes de análisis y el segundo a formular la situación, el tercer encuentro se dedicó a analizar la comparativa de las leyes de las diferentes CC.AA (realizada previamente

14. Los autores del artículo.

Alternativas. Cuadernos de Trabajo Social, 22, 2015, pp. 93-121 - ISSN 1133-0473 
por los/as observadores/as), y el cuarto encuentro a formular y consensuar las proposiciones para una nueva ley. En cada uno de los encuentros, se realizó un registro por parte de los/as observadores/as que servía para el análisis individual de cada informante y punto de partida del siguiente encuentro.

El análisis documental se ha realizado a partir de las legislaciones más modernas en servicios sociales ${ }^{15}$ de España, es decir de las Leyes de tercera generación. Se ha intentado que sea lo más detallado posible tanto del conjunto de legislación como de las directrices de planificación de las diversas CC.AA. Estas legislaciones las hemos comparamos con la legislación y la planificación de la C.V. en esta materia.

En éste análisis se ha recogido solamente los ítems substantivos de las diferentes leyes seleccionadas que permiten trazar un panorama global y sirvan de análisis al panel de expertos para formular las propuestas para un futuro marco de Servicios Sociales valenciano.

La comparativa entre legislaciones se plantea en base a; a)las formas de acceso al sistema, b)la estructura funcional y territorial del mismo, c)las metodologías de trabajo y participación que detallan, d)distribución competencial y coordinación, e)calidad y f)financiación, y todo ello bajo la existencia o no de una planificación que ayude a mejorar el sistema.

\section{Resultados}

\subsection{El 'modelo valenciano' de Servicios Sociales}

A continuación se señalan algunas de las características principales del 'Modelo Valenciano' de Servicios Sociales a partir de la sistematización de la información aportada por los/as expertos/as. La tabla se organiza en cuatro columnas, en la primera denominada «características» hace referencia los elementos substantivos de los SS.SS a analizar, la segunda situación valenciana, la tercera implicaciones en el ámbito local y la cuarta observaciones, donde se incorporan datos de otras CC.AA o referencias que contextualicen.

15. Navarra, Cantabria, Catalunya, Galicia, Euskadi, Illes Balears, Aragón, La Rioja, Castilla-La Mancha y Castilla-León, según Vilà (2012: 145) 


\section{Tabla 2. Características del 'Modelo Valenciano' de Servicios Sociales}

\begin{tabular}{|c|c|c|c|}
\hline Características & Situación Valenciana & $\begin{array}{l}\text { Implicaciones en el } \\
\text { ámbito local }\end{array}$ & Observaciones \\
\hline Planificación & $\begin{array}{l}\text { Los únicos documentos } \\
\text { existentes son el Plan de } \\
\text { actuación de Ss.Ss (1989) } \\
\text { y la Mapificación de Ss.ss } \\
\text { (1991) }\end{array}$ & $\begin{array}{l}\text { Se desconocen las } \\
\text { necesidades en su } \\
\text { conjunto, la adecuación } \\
\text { de los recursos y la } \\
\text { justificación de su } \\
\text { ubicación. } \\
\text { Graves desequilibrios } \\
\text { territoriales en la } \\
\text { distribución de los } \\
\text { recursos. } \\
\text { Inexistencia de previsión } \\
\text { y prevención en las } \\
\text { actuaciones. } \\
\end{array}$ & $\begin{array}{l}\text { Las CC.AA, publican } \\
\text { cada cinco años su } \\
\text { planificación estratégica. }\end{array}$ \\
\hline $\begin{array}{l}\text { Coordinación y } \\
\text { cooperación }\end{array}$ & $\begin{array}{l}\text { No existen niveles, } \\
\text { instrumentos, ni } \\
\text { protocolos que } \\
\text { favorezcan la } \\
\text { coordinación y } \\
\text { cooperación entre } \\
\text { la Generalitat, las } \\
\text { Diputaciones y los } \\
\text { Ayuntamientos. } \\
\text { Tampoco entre lo público } \\
\text { y lo privado. }\end{array}$ & $\begin{array}{l}\text { No es posible racionalizar } \\
\text { ni optimizar los escasos } \\
\text { servicios y programas } \\
\text { existentes. } \\
\text { La ciudadanía sufre } \\
\text { la descoordinación } \\
\text { pues la resolución de } \\
\text { múltiples situaciones } \\
\text { y expedientes requiere } \\
\text { de la cooperación } \\
\text { institucional. }\end{array}$ & $\begin{array}{l}\text { Otras CC.AA, han } \\
\text { aprobado normativas } \\
\text { para garantizar } \\
\text { la coordinación } \\
\text { y cooperación } \\
\text { institucional. }\end{array}$ \\
\hline Participación & $\begin{array}{l}\text { El Consejo Valenciano de } \\
\text { B.S., existe formalmente } \\
\text { pero sin contenido. } \\
\text { Se han creado consejos } \\
\text { sectoriales (mayor, etc.), } \\
\text { pero sin contenido. }\end{array}$ & $\begin{array}{l}\text { Existen Ayuntamientos } \\
\text { donde se han creado } \\
\text { estructuras de } \\
\text { participación (p.e. } \\
\text { Ayto Valencia Taules } \\
\text { de Solidaritat) pero } \\
\text { en la mayoría no se } \\
\text { han creado, o sólo } \\
\text { formalmente. }\end{array}$ & $\begin{array}{l}\text { Cada grupo de interés } \\
\text { (asociaciones, etc.) } \\
\text { impulsa sus acciones y } \\
\text { acuerda su financiación, } \\
\text { perdiendo la visión } \\
\text { holística. }\end{array}$ \\
\hline $\begin{array}{l}\text { Prestaciones y } \\
\text { Servicios }\end{array}$ & $\begin{array}{l}\text { Inexistencia de Catálogo } \\
\text { y Cartera de Servicios y } \\
\text { prestaciones del sistema, } \\
\text { donde se regula la } \\
\text { extensión e intensidad. }\end{array}$ & $\begin{array}{l}\text { En cada Ayuntamiento } \\
\text { y en función de } \\
\text { sus posibilidades, } \\
\text { sensibilidad política, } \\
\text { impulso profesional, } \\
\text { etc., se implantan unos } \\
\text { programas o servicios, } \\
\text { se desarrollan de una } \\
\text { manera u otra, o no se } \\
\text { desarrollan. }\end{array}$ & $\begin{array}{l}\text { En las CC.AA se han } \\
\text { publicado catálogos y } \\
\text { carteras de Servicios } \\
\text { y Prestaciones donde } \\
\text { se identifican titular, } \\
\text { extensión e intensidad. } \\
\text { Los niveles básicos y } \\
\text { complementarios de las } \\
\text { prestaciones. }\end{array}$ \\
\hline
\end{tabular}




\begin{tabular}{|c|c|c|c|}
\hline Características & Situación Valenciana & $\begin{array}{l}\text { Implicaciones en el } \\
\text { ámbito local }\end{array}$ & Observaciones \\
\hline Evaluación & $\begin{array}{l}\text { No existe ningún } \\
\text { documento que evalué el } \\
\text { sistema. } \\
\text { No se han implantado } \\
\text { sistemas de calidad, } \\
\text { donde se recaben las } \\
\text { aportaciones de los } \\
\text { grupos de interés: } \\
\text { profesionales, usuarios/ } \\
\text { as y entidades de acción } \\
\text { social. } \\
\text { La C.V es la única que no } \\
\text { dispone de un análisis de } \\
\text { datos del SIUSS. }\end{array}$ & $\begin{array}{l}\text { Los ayuntamientos no } \\
\text { disponen de estándares } \\
\text { de calidad sobre los que } \\
\text { analizar y evaluar sus } \\
\text { servicios y prestaciones. } \\
\text { Cada Ayto elabora su } \\
\text { propia forma de recoger } \\
\text { los datos, y analizarlos. } \\
\text { Existe Ayuntamientos } \\
\text { en los que no se ha } \\
\text { implantado o se ha hecho } \\
\text { muy deficientemente el } \\
\text { SIUSS. }\end{array}$ & $\begin{array}{l}\text { Las CC.AA, han } \\
\text { implantado el SIUSS en } \\
\text { todos los ayuntamientos } \\
\text { y las memorias se } \\
\text { elaboran a partir del } \\
\text { mismo. } \\
\text { Existen planes de } \\
\text { Calidad, para reconocer y } \\
\text { aplicar estándares. }\end{array}$ \\
\hline $\begin{array}{l}\text { Apoyo Técnico, } \\
\text { soporte y } \\
\text { supervisión }\end{array}$ & $\begin{array}{l}\text { No existen mapas } \\
\text { de procesos ni } \\
\text { procedimientos } \\
\text { unificados. } \\
\text { No existen equipos de } \\
\text { supervisión profesional y } \\
\text { de análisis del sistema. } \\
\text { Sólo existen para } \\
\text { actuaciones sectoriales: } \\
\text { violencia de género, } \\
\text { maltrato infantil, ... }\end{array}$ & $\begin{array}{l}\text { Cada ayuntamiento ha } \\
\text { desarrollado sus procesos } \\
\text { y procedimientos. } \\
\text { Se ahonda cada vez más } \\
\text { en la desigualdad entre } \\
\text { los municipios y por } \\
\text { ende entre la ciudadanía. } \\
\text { Prevalencia de la } \\
\text { inercia institucional y } \\
\text { burocrática. }\end{array}$ & $\begin{array}{l}\text { Otras CC.AA, han } \\
\text { desarrollado mapas } \\
\text { de procesos y } \\
\text { procedimientos para cada } \\
\text { uno de los Servicios y } \\
\text { prestaciones. } \\
\text { Existen equipos de } \\
\text { supervisión profesional. }\end{array}$ \\
\hline $\begin{array}{l}\text { Financiación de } \\
\text { los SS.SS de las } \\
\text { Corporaciones } \\
\text { Locales }\end{array}$ & $\begin{array}{l}\text { No existen convenios } \\
\text { plurianuales para } \\
\text { el sostenimiento de } \\
\text { estructuras y equipos } \\
\text { permanentes. } \\
\text { Incumplimiento del } \\
\text { sistema pactado en el } \\
\text { Plan Concertado del } 33 \% \\
\text { de cada administración. } \\
\text { Se invierte } 212,15 € \text { (entre } \\
\text { Generalitat y Aytos). }\end{array}$ & $\begin{array}{l}\text { Los ayuntamientos cada } \\
\text { año se encuentran con la } \\
\text { incertidumbre, de cuanta } \\
\text { financiación dispondrán } \\
\text { para los servicios y } \\
\text { prestaciones. } \\
\text { Los ayuntamientos } \\
\text { sostienen el 70\% el } \\
\text { sistema, frente al 20\% la } \\
\text { Generalitat y el 10\% el } \\
\text { Ministerio. } \\
\text { Cada ayuntamiento } \\
\text { destina en función de su } \\
\text { capacidad, compromiso y } \\
\text { sensibilidad. } \\
\text { Infrafinanciación e } \\
\text { inestabilidad en el } \\
\text { sistema. }\end{array}$ & $\begin{array}{l}\text { En otras CC.AA (p.e. } \\
\text { Extremadura, Castilla y } \\
\text { León, etc.), es la CA la } \\
\text { principal financiadora del } \\
\text { sistema (aprox. 60-70\%). } \\
\text { La media anual de } \\
\text { inversión en España es } \\
331,41 € x \text { xab (País Vasco } \\
554,64 € x \text { hab). }\end{array}$ \\
\hline
\end{tabular}




\begin{tabular}{|c|c|c|c|}
\hline Características & Situación Valenciana & $\begin{array}{l}\text { Implicaciones en el } \\
\text { ámbito local }\end{array}$ & Observaciones \\
\hline $\begin{array}{l}\text { Reconocimiento } \\
\text { de derechos y } \\
\text { modelo }\end{array}$ & $\begin{array}{l}\text { Prácticamente todas las } \\
\text { prestaciones se hallan } \\
\text { dentro de un modelo } \\
\text { de asistencia social, es } \\
\text { decir, vinculadas a que } \\
\text { haya presupuesto y más } \\
\text { basadas en lo económico } \\
\text { que en las intervenciones } \\
\text { profesionales }\end{array}$ & $\begin{array}{l}\text { Los ayuntamientos } \\
\text { necesariamente han } \\
\text { de desarrollar un } \\
\text { modelo prestacionista y } \\
\text { asistencial. } \\
\text { Cada vez existen } \\
\text { menos intervenciones } \\
\text { profesionales y más } \\
\text { prestaciones dinerarias. }\end{array}$ & $\begin{array}{l}\text { Las CC.AA, más } \\
\text { avanzadas se han } \\
\text { decantado por un modelo } \\
\text { basado en el derecho } \\
\text { subjetivo y por la } \\
\text { intervención profesional } \\
\text { y en red. }\end{array}$ \\
\hline $\begin{array}{l}\text { Profesionales y } \\
\text { equipos }\end{array}$ & $\begin{array}{l}\text { No existe por parte de } \\
\text { la Generalitat ningún } \\
\text { análisis sobre la ratios } \\
\text { necesarias, en función de } \\
\text { población etc. } \\
\text { La Ratio de población } \\
\text { por UTS es en la C.V. de } \\
\text { unos } 22.000 \text { hab. }\end{array}$ & $\begin{array}{l}\text { Cada ayuntamiento } \\
\text { destina en función de su } \\
\text { capacidad, compromiso y } \\
\text { sensibilidad. } \\
\text { Sobrecarga y saturación } \\
\text { profesional. }\end{array}$ & $\begin{array}{l}\text { La ratio de UTS (media } \\
\text { española) es de } 9.000 \\
\text { hab. } \\
\text { La Rioja es la mejor } \\
\text { posicionada con } 1.185 \\
\text { hab x UTS y Catalunya la } \\
\text { más cercana con } 12.500 \\
\text { Hab x UTS. }\end{array}$ \\
\hline $\begin{array}{l}\text { Organización } \\
\text { funcional }\end{array}$ & $\begin{array}{l}\text { Solo existen dos } \\
\text { niveles; generales y } \\
\text { especializados. } \\
\text { El salto de la atención } \\
\text { de lo primario a lo } \\
\text { especializado/ residencial } \\
\text { es excesivo, sin un nivel } \\
\text { que ayude a que las } \\
\text { actuaciones no deban } \\
\text { salir del ámbito de } \\
\text { residencia habitual del } \\
\text { ciudadano/a }\end{array}$ & $\begin{array}{l}\text { El necesario nivel } \\
\text { intermedio ha tenido } \\
\text { que ser impulsado } \\
\text { y financiado por } \\
\text { los Ayuntamientos. } \\
\text { Tiene escaso apoyo o } \\
\text { reconocimiento por parte } \\
\text { de la Generalitat. } \\
\text { La gran mayoría de } \\
\text { municipios de la C.V } \\
\text { carecen de este nivel } \\
\text { intermedio. }\end{array}$ & $\begin{array}{l}\text { Todas las CC.AA } \\
\text { disponen de tres niveles; } \\
\text { comunitarios, específicos } \\
\text { y especializados. } \\
\text { El pase de una atención } \\
\text { primaria a una muy } \\
\text { especializada es un } \\
\text { sobre coste del sistema } \\
\text { actual y potencia su } \\
\text { mercantilización }\end{array}$ \\
\hline $\begin{array}{l}\text { Organización } \\
\text { territorial }\end{array}$ & No existe & $\begin{array}{l}\text { Cada ayuntamiento } \\
\text { o agrupación de } \\
\text { los mismos se ha } \\
\text { desarrollado a su libre } \\
\text { albedrío. } \\
\text { Abandono de los } \\
\text { municipios rurales. }\end{array}$ & $\begin{array}{l}\text { Todas las CC.AA lo han } \\
\text { legislado estableciendo } \\
\text { Zonas de Ss. Ss (con } \\
\text { unos } 20.000 \text { hab) y } \\
\text { Áreas de Ss.Ss (con unos } \\
\text { 100.000hab) }\end{array}$ \\
\hline $\begin{array}{l}\text { Autonomía y } \\
\text { Dependencia }\end{array}$ & $\begin{array}{l}\text { Creación de un sistema } \\
\text { paralelo al de Ss.Ss. } \\
\text { Irrelevante implantación } \\
\text { del sistema: prevalencia } \\
\text { de la prestación } \\
\text { económica sobre los } \\
\text { servicios, el limbo }{ }^{1} \text { de la } \\
\text { dependencia. } \\
\text { Normativa propia más } \\
\text { restrictiva que la estatal. } \\
\text { La C.V invierte } 62.21 € x \\
\text { hab/año en el sistema }\end{array}$ & $\begin{array}{l}\text { Los Smad's no se adaptan } \\
\text { a la demarcación de } \\
\text { los servicios sociales } \\
\text { municipales. } \\
\text { La atención se escora } \\
\text { hacia prestaciones } \\
\text { vinculadas al servicio } \\
\text { en lugar de servicios } \\
\text { públicos propios que } \\
\text { generarían empleo. }\end{array}$ & $\begin{array}{l}\text { Otras CC.AA han } \\
\text { implantado la } \\
\text { dependencia dentro del } \\
\text { sistema de Ss.Ss. } \\
\text { Tenemos una puntuación } \\
\text { de } 0,4 \text { sobre } 10 \text {, mientras } \\
\text { que la media de las } \\
\text { CC.AA es de } 4,7 \text {, y la } \\
\text { mejor valorada, Castilla y } \\
\text { León, cuenta con un } 9,6 .{ }^{2} \\
\text { La media de inversión de } \\
\text { las CC.AA hab/año es de } \\
\text { 109.25€, y la de mayor } \\
\text { inversión es Cantabria } \\
\text { con } 174.35 € \text {. }\end{array}$ \\
\hline
\end{tabular}


Servicios Sociales en la Comunitat Valenciana: el actual 'modelo valenciano' y una... 103

\begin{tabular}{|l|l|l|l|}
\hline Características & \multicolumn{1}{|c|}{ Situación Valenciana } & \multicolumn{1}{|c|}{$\begin{array}{c}\text { Implicaciones en el } \\
\text { ámbito local }\end{array}$} & \multicolumn{1}{c|}{ Observaciones } \\
\hline $\begin{array}{l}\text { Rentas } \\
\text { Mánimas: renta } \\
\text { ciudadanizada de }\end{array}$ & $\begin{array}{l}\text { Derecho subjetivo no } \\
\text { garantizado. } \\
\text { Criterios de inclusión } \\
\text { restrictivos. } \\
\text { Sin profesionales } \\
\text { ni programas de } \\
\text { acompañamiento. }\end{array}$ & $\begin{array}{l}\text { Diferentes decisiones } \\
\text { políticas: municipios } \\
\text { con convenio y } \\
\text { otros sin convenio, } \\
\text { con repercusiones } \\
\text { importantes en el abono } \\
\text { de la prestación a las } \\
\text { personas. } \\
\text { Sobrecarga de los y las } \\
\text { profesionales. }\end{array}$ & $\begin{array}{l}\text { Según datos de } 2011^{3} \\
\text { la C.V tenía } 16.982 \\
\text { beneficiarios frente a } \\
\text { los 52.425 de Madrid } \\
\text { que tiene una población } \\
\text { similar a la valenciana y } \\
\text { menor tasa de pobreza }\end{array}$ \\
\hline
\end{tabular}

1. Denominación otorgada por la Asociación Estatal de Directoras y Gerentes de Servicios Sociales que hace referencia a los expedientes de la dependencia en el trascurso del tiempo desde su solicitud a su resolución.

2. Datos de XII Dictamen de la Dependencia (Enero 2014), realizado por la Asociación Estatal de Directoras y Gerentes de Servicios Sociales

3. Datos del Informe de rentas mínimas de inserción (2011). Mํo Sanidad, Servicios Sociales e Igualdad

Fuente: elaboración propia

Una primera panorámica de los SS.SS valencianos es su alejamiento del encuadre de los derechos sociales, fundamentalmente debido a las políticas públicas de la Generalitat Valenciana, ya que todavía no ha concretado un marco de derecho subjetivo como otras CC.AA. Asimismo, el sistema se halla débilmente articulado, pues la Ley 5/97 no ha sido prácticamente desarrollada.

Un hecho reciente que avala esta conclusión es la publicación de la Ley 4/2012 sobre los Derechos Sociales en la Comunitat Valenciana, que es una muestra más de la ausencia de derechos subjetivos porque se limita a describir todo una cartera de servicios sin acompañamiento presupuestaria, ni vinculación institucional y sin garantía de los derechos sociales.

\subsection{Comparativa de modelos de Servicios Sociales de las CC.AA frente a la Comunitat Valenciana}

Las tablas comparativas realizadas son extensas, dado que analizamos 11 CC.AA y 6 grandes ítems, pero es clave aportarlas en este artículo, ya que comparadas unas CC.AA con otras se puede deducir el esfuerzo en planificación, legislación, ordenación y financiación que hacen cada una de ellas. 


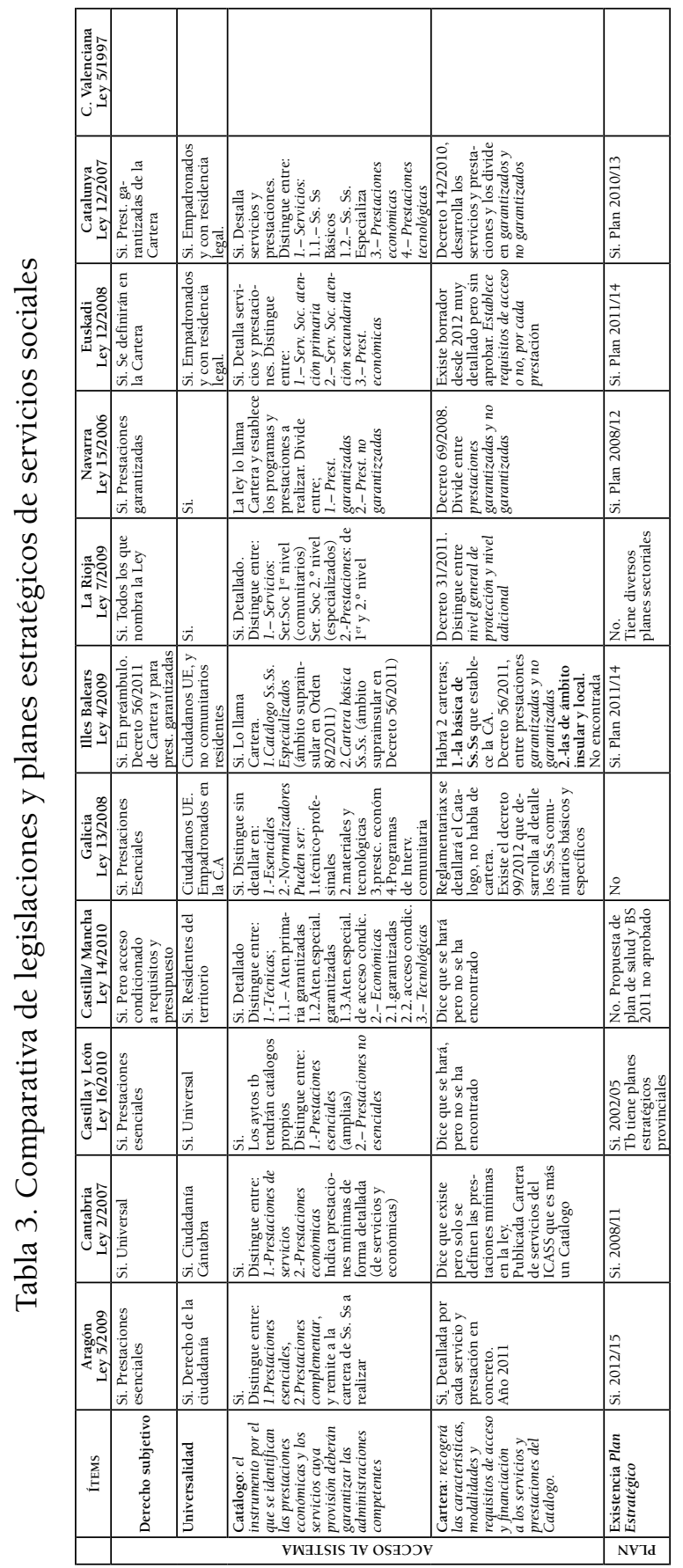

Alternativas. Cuadernos de Trabajo Social, 22, 2015, pp. 93-121 - ISSN 1133-0473 DOI: 10.14198/ALTERN2015.22.06 
Servicios Sociales en la Comunitat Valenciana: el actual 'modelo valenciano' y una... 105

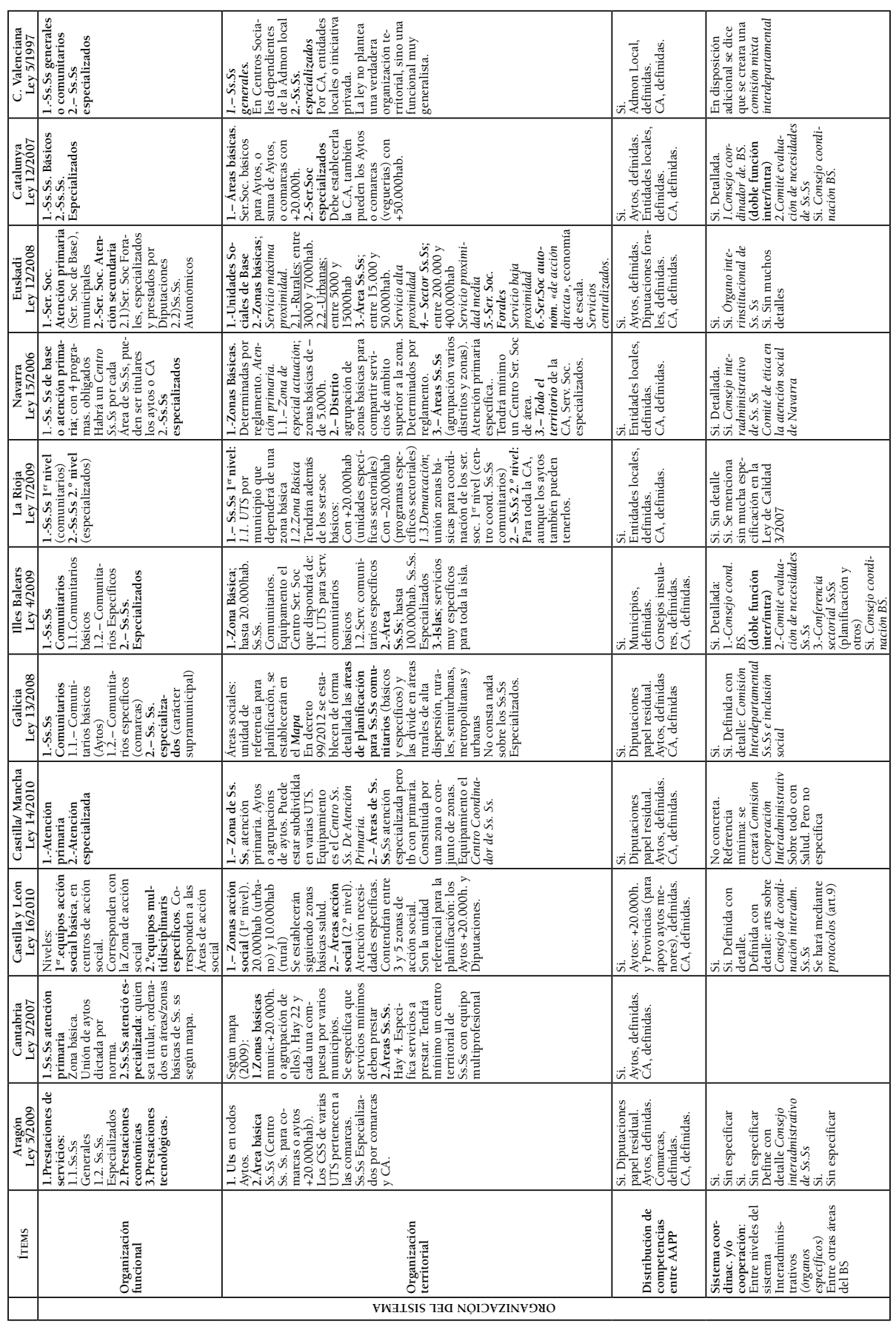

Alternativas. Cuadernos de Trabajo Social, 22, 2015, pp. 93-121 - ISSN 1133-0473 DOI: 10.14198/ALTERN2015.22.06 


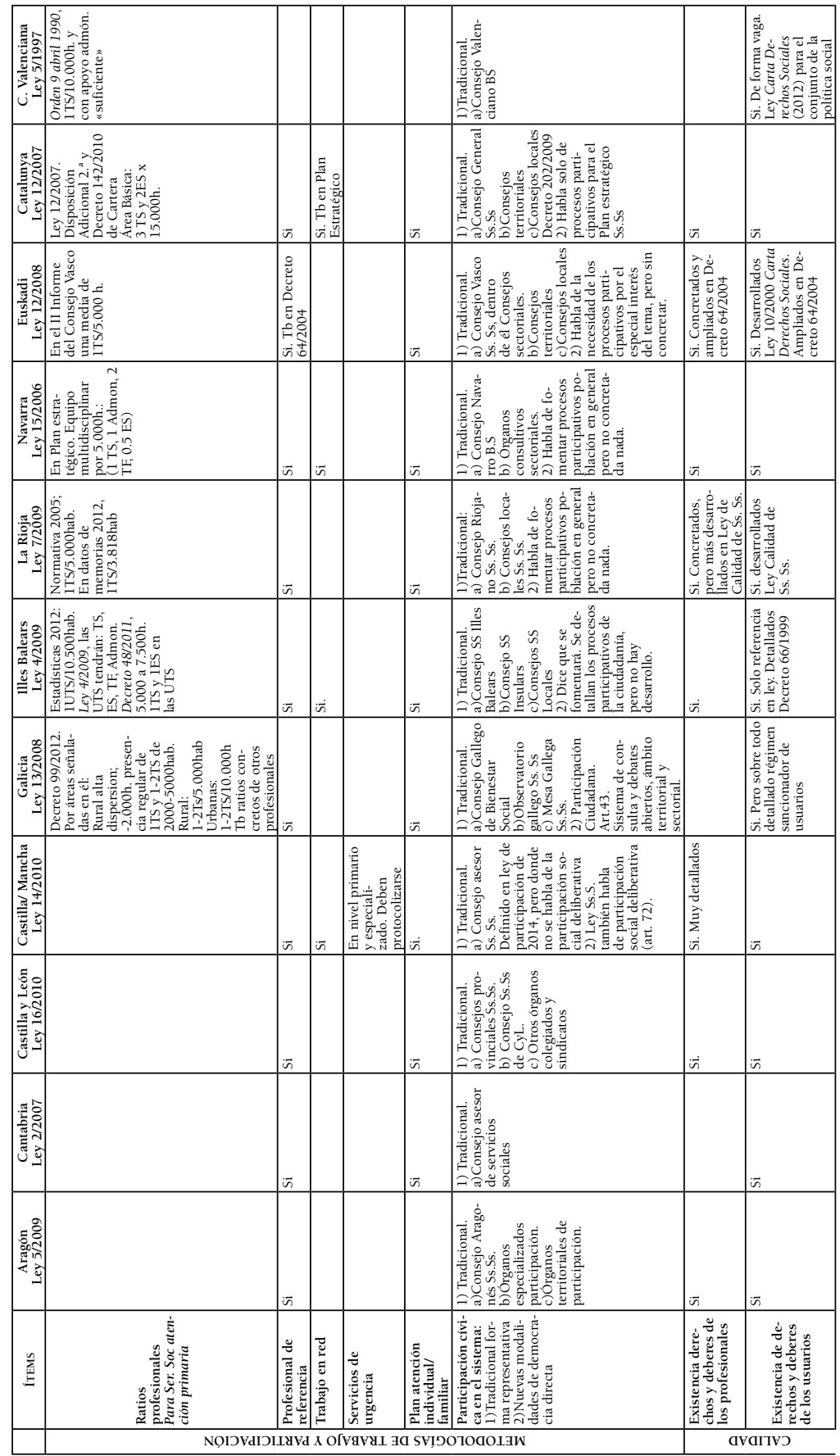

Alternativas. Cuadernos de Trabajo Social, 22, 2015, pp. 93-121 - ISSN 1133-0473 DOI: 10.14198/ALTERN2015.22.06 


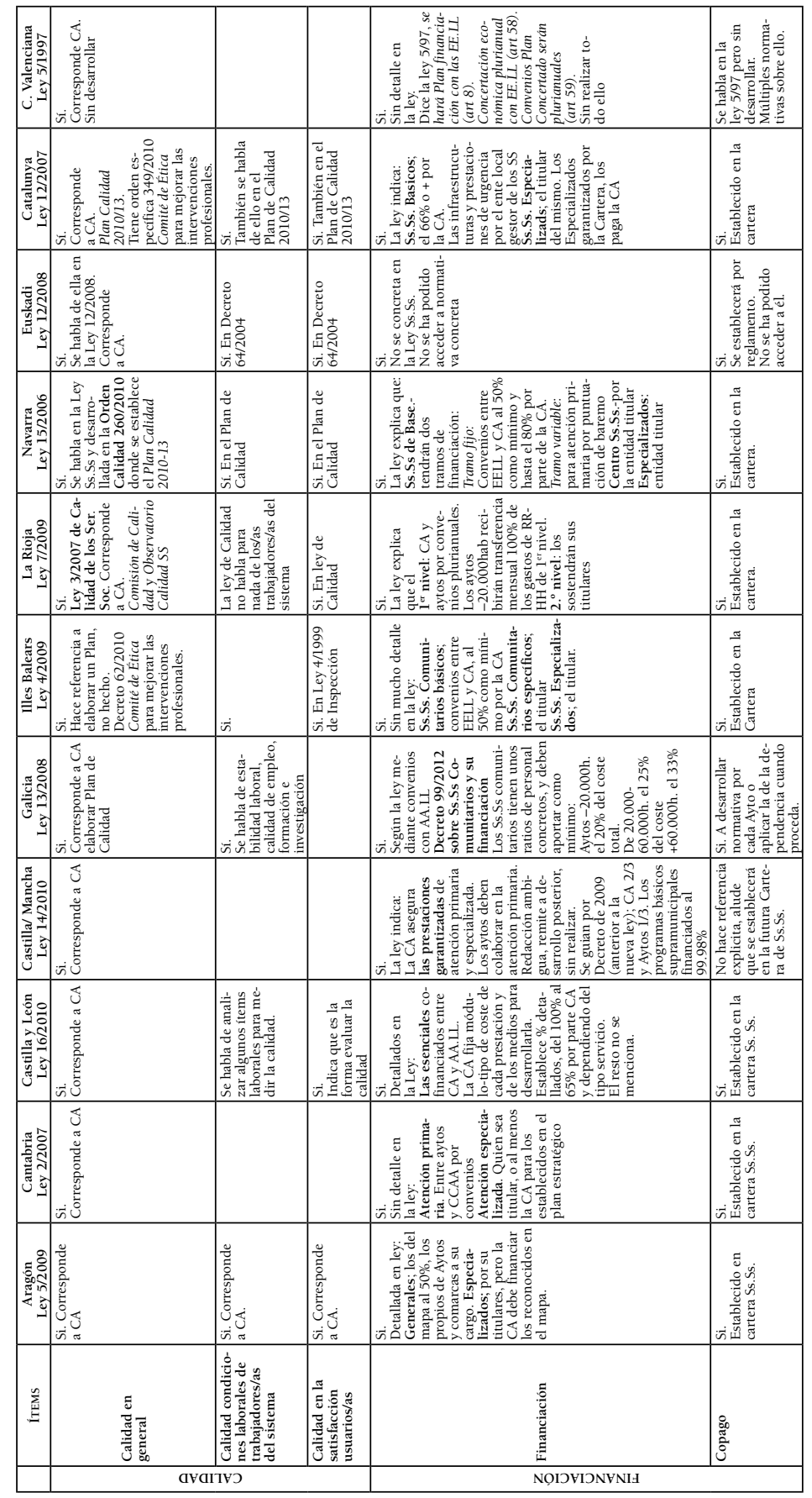

Alternativas. Cuadernos de Trabajo Social, 22, 2015, pp. 93-121 - ISSN 1133-0473 DOI: 10.14198/ALTERN2015.22.06 
Este análisis nos desvela que el ACCESO AL SISTEMA está definido de forma genérica como acceso universal para el conjunto de la población, aunque todas matizan que residentes legales o ciudadanos de la UE, dejando explícitamente fuera a los inmigrantes/residentes/extranjeros ilegales. La C.V. utiliza las denominaciones poco precisas de «valencianos/as, transeúntes y extranjeros con tratado de reciprocidad» y respecto a la situación de los inmigrantes irregulares numerosas órdenes los excluyen de las prestaciones principales.

El conjunto de legislaciones analizadas mencionan que se basan en el derecho subjetivo de uso de prestaciones del sistema, pero enseguida aclaran que este derecho subjetivo solo es referente a las prestaciones que la propia ley o que sus catálogos de desarrollo determinen como esenciales o garantizadas. En la C. V. el derecho subjetivo es inexistente en todos los ámbitos de los servicios sociales. De hecho el índice DEC $2013^{16}$ otorga a esta comunidad un cero absoluto en el apartado de derechos y decisión política.

Con respecto a la existencia de un Catálogo de Servicios Sociales y de una Cartera de Servicios Sociales, cabe destacar que todos mencionan ambos instrumentos y casi todas los tienen bien desarrollados. El instrumento menos desarrollado es la Cartera, falta en algunos de ellos. Se ha generado la legislación para concretar la cartera de servicios que han de otorgar las entidades locales, pero en algunas ocasiones falta definir los propios de su responsabilidad (véase Galicia e Illes Balears).

Sobre la existencia de Catálogo o Cartera de Servicios Sociales en la C.V, ni se menciona la posibilidad de su existencia en la Ley 5/97 ni en ningún otro documento/Decreto/orden que se haya realizado en los últimos 30 años.

Sobre la existencia de una Planificación en SERvicios Sociales se detecta la inclusión de la misma en las diversas CC.AA. Casi todas disponen de planes estratégicos ${ }^{17}$, bien de servicios sociales o sectoriales, que unificados pueden dar una planificación integral del sistema, pero la Comunitat Valenciana aunque lo menciona en su art 5 de la Ley 5/97 de Servicios Sociales como competencia de la Generalitat, nunca ha realizado ningún intento planificador. La última planificación conocida es del años 1990-1991, en Domenech y García (1990).

Sobre LA ORGANIZACIÓN DEL SISTEMA todos tienen una similar organización funcional de servicios sociales de atención primaria o comunitaria, basados

16. Índice de Desarrollo de los Servicios Sociales 2013. Índice basado en el análisis de los derechos y decisión política (D), la relevancia económica (E) y la cobertura de servicios a la ciudadanía (C).

17. No se han encontrado para Galicia y Castilla La Mancha, ni por supuesto para la Comunitat Valenciana. 
en atender a la ciudadanía en su entorno habitual y que en varios casos se subdividen en básicos -haciendo referencia a los que definía el PCPB- y específicos para mencionar aquellos que han ido apareciendo con los años y que se prestan con una mayor intensidad o especialización que los anteriores pero siempre dentro de un trabajo comunitario, y los servicios sociales especializados, que ya se prestan fuera del ámbito de residencia del ciudadano/a, basados en la asistencia un recurso de tipo más residencial y con una intensidad de prestación elevada.

La organización territorial en el conjunto de las leyes se basa en la creación de zonas básicas de servicios sociales (con unos 20.000hab. y encargada de los servicios comunitarios básicos) y áreas de servicios sociales que contendrán varias zonas básicas de servicios sociales (la media poblacional para ellas que se menciona en la diversas leyes y planificaciones es de 100.000hab. y es donde se prestaran los servicios comunitarios más específicos). La prestación de los servicios sociales especializados que corresponden a las CC.AA está reflejada en las diversas planificaciones y se realiza en base al tipo de servicio y las necesidades de las zonas en concreto, observándose en el análisis documental realizado que casi siempre son fruto de una planificación estratégica donde han trabajado tanto ciudadanos/as como técnicos/as y administración pública.

Esta organización territorial no está realizada en la Comunitat Valenciana.

El apartado de coordinación y cooperación intra sistema o entre sistemas del bienestar es bastante conciso en las legislaciones y normas de desarrollo consultadas, ya que aunque se hace referencia a él y se habla de los distintos consejos o comités que se encargarán de su desarrollo, solo Navarra detalla como debe funcionar esa coordinación. En algunas legislaciones se establece que el principio de prevalencia de criterio de atención social lo poseen los servicios sociales comunitarios básicos, pero es la única norma de funcionamiento, que no coordinación, que se menciona concretamente.

Con respecto a las METODOLOGÍAS DE TRABAJO Y PARTICIPACIÓN analizadas remitimos a las tablas realizadas donde lo destacable es que los/as ciudadanos/ as tienen derecho a un profesional de referencia y un plan de atención social individual/familiar, que el ratio es de un trabajador social por cada 5.000 habitantes (media para los servicios comunitarios básicos), que pocos mencionan el trabajo en red y que solo Castilla-La Mancha menciona la existencia de un servicio social de urgencia. Respecto a la C.V., no existe referencias, ni preocupaciones metodológicas que se hayan plasmado en documentos posteriores a la Ley $5 / 97$. 
Con respecto a la participación de los/as ciudadanos/as en el sistema todas las leyes la plantean de forma tradicional mediante representatividad en Consejos, pocos mencionan la participación ciudadana directa, y cuando lo hacen es para hablar de ello de forma difusa y posponerla a un desarrollo posterior.

El apartado de CALIDAD está bastante desarrollado en las legislaciones consultadas, en sus planes estratégicos, e incluso algunas CC.AA tienen legislación o planificación estratégica específica para ello. Se puede ver que la preocupación por la calidad es una constante.

Sobre la FINANCIACIÓN del sistema pocas CC.AA especifican en su legislación como la realizarán, remitiéndose casi todos a la frase de «se establecerá mediante convenios». Solo honrosas excepciones como Castilla-León y Galicia la detallan por ley. Estas legislaciones solo hacen referencia concreta a la financiación de los servicios comunitarios (básicos y específicos) dejando los servicios sociales especializados «a cargo de la entidad que sea su titular», que en principio será la C.A.

\section{Discusión}

\section{1. el 'Modelo Valenciano' de Servicios Sociales}

En lo que respecta al 'Modelo Valenciano' de Servicios Sociales que tanto mencionamos, solo cabe decir que en realidad no existe un modelo que pueda ser reconocido como tal y tomado de referencia, más bien por su carencia de ordenación, fragmentación, ausencia de planificación y falta de concreción, es un antimodelo.

El sistema se sigue ordenando por la Ley 5/97, aunque no se ha desarrollado esta Ley en los puntos que ella misma indica ${ }^{18}$, y el día a día del 'modelo' se rige por decretos y órdenes totalmente desfasadas ${ }^{19}$.

En la Ley 5/97 de Servicios Sociales de la Comunitat Valenciana hay un reparto de las competencias entre la Generalitat y las entidades locales, dando a las Diputaciones la competencia de apoyar a los municipios de menos de 10.000hab. Ni en ella, ni en desarrollos legislativos posteriores, se plantea

18. Baste con mencionar; el art.5.a) «elaborar un plan general de servicios sociales de carácter plurianual», el 5.c) «establecer las prioridades tanto en la programación de las actuaciones como de las inversiones que deban realizarse en los equipamientos de servicios sociales, 5.d) «establecer unos mínimos de calidad que ha cumplir todos los centros y servicios de servicios sociales, 5.m) «desarrollar reglamentariamente la presente ley y dictar cuantas disposiciones se requieren para su aplicación»,...

19. Como ejemplo aún sigue en vigor parte de la Orden del 9 de abril de 1990, sobre registro, autorización y acreditación de los Ss.Ss en la C.V. 
un nivel intermedio de servicios sociales entre lo local y lo autonómico, los llamados -servicios sociales específicos-, como si sucede en otras CC.AA, y ha sido el nivel local el que ha desarrollado numerosos programas específicos, que superan su capacidad, en sectores como la infancia, mujer, exclusión social, tercera edad,..., generando obligaciones y costes que corresponden a la Generalitat Valenciana. Para los servicios sociales especializados tampoco existe documento de planificación. La organización territorial de los servicios sociales valencianos es una asignatura pendiente después de 20 años.

El irrelevante desarrollo de los servicios sociales valencianos ha hecho que el peso de los mismos recaiga sobre las administraciones locales, y esto conlleva que los ayuntamientos y mancomunidades en función de su capacidad, compromiso y sensibilidad, hayan tenido que desarrollar y apoyar numerosos servicios y prestaciones de forma dispar, instaurándose una gran desigualdad entre vecinos/as de diferentes municipios, asentándose un modelo asistencial, sin prevención ni intervención profesional, sin referencias territoriales ni directrices políticas ni técnicas claras, y con numerosas deficiencias. La obligación de planificación estratégica y el cumplimiento de las COMPETENCIAS DE la Generalitat Valenciana en Servicios Sociales según el art.5 de la Ley 5/1997, es inexistente.

'El modelo valenciano' constituye un ejemplo evidente de inestabilidad, improvisación, falta de planificación y desinterés de los/as políticos/as por los servicios sociales, esto se puede vislumbrar en el hecho de que al frente de la Conselleria de Bienestar Social, y pese estar gobernada la Generalitat por el mismo partido desde el año 1995, ha habido nueve Consellers/es (un promedio de uno cada dos años y de ellos/as cuatro condenados/as o imputados/ as ${ }^{20}$. Cada uno con diferentes gabinetes técnicos y políticos, y que nunca han tenido en su agenda una planificación estratégica del sistema.

\subsection{Comparativa de modelos de Servicios Sociales de las diversas CC.AA}

En lo referente a un análisis comparativo entre las legislaciones de servicios sociales de tercera generación de servicios sociales y la legislación de la Comunitat Valenciana, la discusión a proponer aquí es más bien escasa, ya que los resultados sistematizados son elocuentes.

20. José Sanmartín (1995-1997); Marcela Miró (1997-1999); Carmen Mas (1999-2000); Rafael Blasco (2000-2003) «condenado por Caso Cooperación»; Alicia de Miguel (2003-2007) «imputada Caso Gürtel»; Juan Cotino (2007-2009) «relacionado Caso Gürtel, Emarsa y Brugal»; Angélica Such (2009-2011) «imputada Caso Gürtel»; Jorge Cabré (2011-2012) y Asunción Sánchez (2012- actualidad). 
Solo mencionar que en apartados como el ACCESO AL SISTEMA, no existen Catálogo y Cartera de servicios, no son visibles los recursos existentes, no se concreta el acceso a ellos, de quien dependen, etc. El sistema valenciano sigue anclado desde el punto de vista del derecho en lo asistencial y en ocasiones en lo benéfico. Los derechos subjetivos no existen en la Comunitat Valenciana.

Respecto a la ORGANIZACIÓN DEL SISTEMA destacar que es necesaria una organización funcional urgente ya que el nivel intermedio de los servicios sociales específicos no existe de forma organizada y se está desarrollando por cada Ayuntamiento, creando por su cuenta servicios específicos que les es difícil de mantener y que van a desaparecer con la aplicación de la LRSAL, o que en muchos casos ni siquiera se han creado, ya que no existe planificación que lo decida ni lo obligue, configurándose así una división entre pueblos de primera y segunda categoría en cuanto a servicios sociales. La subdivisión funcional de los servicios comunitarios en básicos, a prestar por los ayuntamientos o mancomunidades, y en comunitarios específicos, a prestar por comarcas, sería la acertada a la realidad poblacional de nuestra Comunidad. La necesidad de planificación autonómica en el sistema de servicios sociales es abrumadora.

En lo referente a CALIDAD es preciso el establecimiento de estándares de calidad y máxime cuando casi todos los servicios sociales específicos y especializados son prestados por entidades de titularidad privada pero pagados con fondos públicos, ya que la única legislación de la que disponemos al respecto, el decreto 90/2002 sobre control de la calidad de los centros y servicios de acción social y entidades evaluadoras de la misma, solo habla de quién es considerado apto para controlar la calidad de los centros y programas de los servicios sociales, pero no de cuál debe ser esta calidad. El articulado de este decreto 90/2002 solo versa sobre la obligación de que todas las personas físicas o jurídicas, públicas o privadas, que trabajen en el campo de la acción social en la C.V, deben pasar controles de calidad (arts. 1 al 5) y a partir del art. 6 hasta el final de la norma se limita a describir quién puede ser entidad evaluadora de calidad y los procedimientos para obtener dicha acreditación de entidad evaluadora (se establece quién evaluará, sin saber qué se va a evaluar).

Sobre la inexistencia de LEGISLACIÓN SOBRE FINANCIACIÓN en la Comunitat Valenciana no cabe decir mucho, solo que no existe, y ello es consecuencia directa de cómo se valora este sistema en la agenda política de la Generalitat Valenciana.

Como finalización de esta discusión solo cabe citar de forma textual a Mira-Perceval, De Alfonseti, y Giménez Bertomeu, que resumen de forma magistral cuál es nuestro 'modelo valenciano' de servicios sociales,

En los más de veinte años de existencia del sistema de Servicios Sociales en la Comunidad Valenciana, ha existido una permanente disociación entre 
las formulaciones políticas respecto a los Servicios Sociales desde el punto de vista de sus fines y principios, por una parte, y la aplicación práctica de las mismas en cuanto a los medios arbitrados y efectos en los grupos socialmente diferenciados, por otra. Los Servicios Sociales, lejos de alcanzar las amplias aspiraciones apuntadas en la normativa que los regula, se han manifestado incapaces de dar respuesta a la importante demanda propiciada por los cambios sociales recientes y el sistema construido no consigue desvincularse de su imagen social de sistema de protección residual, orientado a dar respuesta a las necesidades más extremas de determinados colectivos o sectores de población. (2007: 69)

\section{Conclusiones}

La finalidad última de esta parte de la investigación era realizar una propuesta genérica sobre unas nuevas bases para la construcción de un nuevo Sistema de Servicios Sociales en la Comunitat Valenciana aprovechando las posibles «circunstancias positivas ${ }^{21}$ que se podrían derivar de la aprobación de la LRSAL y que van en la línea de crear una legislación para los servicios sociales, a continuación exponemos las grandes líneas maestras que han resultado de este panel de expertos/as en servicios sociales.

\section{1. propuesta para articular los Servicios Sociales valencianos}

El nuevo marco legal para las Administraciones Locales modifica substancialmente su ámbito competencial en materia de Servicios Sociales. Es un buen momento para reivindicar dos cuestiones: 1) la derogación de la LRSAL y 2) la aprobación de una Ley Estatal de Servicios Sociales que establezca el nivel básico común para todos/as los/as ciudadanos/as. En tanto se avanza en lo anterior, la C. V. ya tiene competencias exclusivas en Servicios Sociales según su Estatuto de Autonomía y dispone de un amplio abanico de posibilidades para ordenar el sistema, por lo que se deben iniciar estos trabajos pendientes desde hace muchos años.

A continuación señalaremos los dos ejes para el desarrollo de una Agenda de Servicios Sociales desde la Generalitat Valenciana, las Diputaciones y los

21. Nos referimos aquí al mandato que realiza esta ley que en su Disposición Transitoria Segunda (asunción por las CC.AA de las competencias relativas a Servicios Sociales) donde se indica en el punto «b) Previa elaboración de un plan para la evaluación, reestructuración e implantación de los servicios, las CC.AA. en el ámbito de sus competencias, habrán de asumir la cobertura inmediata de dicha prestación», que puede ser algo positivo para el actual antimodelo valenciano de servicios sociales actual, si se gestiona de forma diferente a lo que se ha estado haciendo en los últimos 20 años. 
Ayuntamientos: 1) Elementos sustantivos del sistema y, 2) Propuestas para una nueva articulación de los Servicios Sociales.

\subsubsection{Elementos sustantivos para unos nuevos servicios sociales}

La Unión Europea considera que las políticas sociales son principalmente responsabilidad de los Estados miembros, entiende que los Servicios Sociales tienen, entre otros, los siguientes objetivos: a) proteger contra los riesgos y apoyar a las familias; b) salvaguardar los derechos humanos fundamentales; c) contribuir a la no discriminación reforzando la igualdad y d) proteger a las personas contribuyendo a la mejora de sus condiciones y calidad de vida, garantizando su autonomía personal y facilitando la plena participación social.

Los servicios sociales deben ser concebidos y prestados de manera integrada desde la proximidad, y de acuerdo con la Comisión Europea: a) se basan en el principio de solidaridad o universalidad; b) dependen de la financiación pública para garantizar la igualdad de acceso; c) son considerados como servicios de interés general; d) garantizan los derechos humanos fundamentales y protegen a las personas más vulnerables; e) expresan la solidaridad ciudadana por la participación del voluntariado y f) están integrados en la tradición cultural o local (proximidad).

Los Servicios Sociales Valencianos deben analizar lo que ha sido su práctica institucional en los últimos treinta años, gestionar el conocimiento producido en el sistema desde el consenso científico y profesional, realizar una mirada hacia las CC.AA más avanzadas y construir su propio modelo desde la participación del conjunto de los actores. En cualquier caso deben reformularse amplia e intensamente desde los siguientes principios: Globalidad, Prevención, Normalización, Integralidad, Transversalidad, Solidaridad, Dimensión Comunitaria, Atención Personalizada, Interdisciplinariedad, Respeto a la Diferencia y a la Diversidad, Subsidiariedad, Integración, Inclusión Social, Autonomía Personal y Participación Ciudadana.

Es imprescindible realizar un Plan Estratégico de Servicios Sociales de la Comunitat Valenciana con la participación del conjunto de los actores del sistema. Es un plan del sistema, no de la Generalitat, ha de incorporar una evaluación previa del estado (Diagnóstico). Son demasiados años sin evaluar, sin conocer las necesidades y sin incorporar a todos/as en el proceso.

El liderazgo del sistema ha de realizarse desde la responsabilidad pública, como elemento vertebrador del sistema, es condición importante para el éxito. Es necesario un liderazgo político (la legitimidad y la decisión de iniciar y mantener el proceso, la gestión del entorno interinstitucional), un liderazgo 
técnico que oriente y coordine el proceso, y un liderazgo ciudadano en la definición de los derechos y su articulación.

Después de un período de virulenta crisis económica, desempleo y recortes en la protección social, la Inclusión Social ha de ser una prioridad, nadie ha de quedarse «tirado en la cuneta». Se ha de garantizar los mínimos vitales, desde el respeto y la normalización, excluyendo políticas sin prevención ni intervención social como las «ayudas nutricionales», y generando una red por la inclusión con los otros sistemas de protección social y las organizaciones y entidades de acción social. La atención integral del ciudadano/a es su fin, y no sólo la atención de causas colaterales y mediáticas.

Alianza entre los actores del sistema, dado que la interdependencia es cada vez más visible y necesaria, desde la honestidad y lealtad institucional, que ayuden a estructurar el sistema y le confieran la imagen de un verdadero sistema de protección social.

Centralidad de la persona en todo el sistema, garantizando sus derechos, acompañándola desde el/la profesional de referencia, y siendo su atención la base del mismo, ya que actualmente lo son las prestaciones, y no las personas y sus necesidades.

5.1.2. Propuestas de articulación de una nueva ley de Servicios Sociales de la comunitat valenciana.

Es necesario aprobar una nueva Ley de Servicios Sociales de la Comunitat Valenciana, que articule un modelo de servicios sociales sobre los elementos sustantivos señalados en el punto primero, que sea fruto de un proceso participativo desde un Plan Estratégico, y que incluya a todos los actores del sistema.

La nueva Ley de Servicios Sociales ha de incorporar dentro del sistema: los servicios sociales (nivel local y autonómico), el sistema de atención para la autonomía personal y las personas en situación de dependencia y, las rentas garantizadas de ciudanía.

Esta nueva Ley ha de basarse en:

a. Derecho Subjetivo, donde se reconozca y garantice la prestación a todas las personas que acrediten necesidad, y no condicionado a presupuestos.

b. Desde un Catálogo del sistema (prestaciones y servicios) y una Cartera, donde se defina la extensión e intensidad.

c. Se defina su organización funcional basada en tres niveles: Atención Primaria, la Específica y la Especializada, definidos desde la 
proximidad al ciudadano/a. El territorio como eje planificador del sistema, articulado en dos niveles: servicios sociales generales (comunitarios y específicos) y servicios sociales especializados.

d. Se estructure la organización territorial de prestación del sistema basada en zonas básicas y áreas de servicios sociales. La Zona Básica presta los servicios sociales de atención primaria y las Áreas para los servicios específicos, siendo la Comunidad Autónoma la responsable de los especializados. Atención especial a los municipios rurales.

e. Se elabore una mapificación de base territorial, donde se anclen los servicios y recursos específicos y especializados, desde criterios de proximidad y necesidad.

f. Se genere una estructura de coordinación interadministrativa e intra administrativa donde se recojan las conexiones locales, comarcales y autonómicas, así como con el resto de sistemas del bienestar, y entre lo público y lo privado.

g. Se identifique y promueva un marco de participación de la ciudadanía en el sistema, y que la utilización del mismo sea real y efectiva.

h. Se acompañe de una financiación local para los servicios sociales básicos y específicos, (afectada, condicionada) y al 100\% para los equipos profesionales. El resto de actuaciones a financiar por convenios que realmente se sujeten a las planificaciones estratégicas y sean seguidos y evaluados en su calidad y oportunidad.

i. Calidad, inspección, mejora continua, formación de profesionales, supervisión y control, (planes de calidad en dos ejes territoriales: local y autonómico), donde haya estándares definidos entre la administración local y la comunidad autónoma, y de cumplimiento para todos aquellos que participen en la gestión del sistema.

j. Potenciar las sinergias y alianzas que se dan dentro del sistema y con el resto de sistemas.

k. Realizar una planificación estratégica basada en el territorio y que sea «de abajo hacia arriba» en el mismo, puesto que la base debe ser la participación de todos los actores implicados desde el conocimiento real y concreto.

1. Realizar un Plan de Inclusión Social a nivel local y autonómico. Debe ser el eje vertebrador de las sinergias y colaboraciones de la atención centrada en las personas, el potenciador de alianzas para evitar las causas sociales de la exclusión, y el generador de empoderamiento de la ciudadanía en sus territorios. 
m. Un sistema basado en los Servicios, como impulsores de la atención social, el desarrollo local y el empoderamiento, frente a un sistema basado en ayudas económicas individualizadas.

n. La prevención de las causas de la exclusión social, por encima de la mera asistencia -lo único que se intenta atender en la Comunitat Valenciana- o la inserción o reinserción social.

\section{Bibliografía}

Aguilar Hendrickson, M. (2013). Los servicios sociales en la tormenta. Documentación Social. N. ${ }^{\circ} 166.145-167$.

Asociación Estatal de Directoras y Gerentes de Servicios Sociales. (2014). Los Servicios Sociales en España 2014. Madrid. Asociación de Directores y Gerentes.

Asociación Estatal de Directoras y Gerentes de Servicios Sociales. (2013). Índice DEC 2013. http://www.directoressociales.com/images/documentos/idec\%20 07.06.2013.pdf. (Consultado el 21/2/2015)

Belis, V. y Moreno, A. (2002). Evolución del sistema de servicios sociales en la comunidad valenciana. Arxius de Ciències Socials, 11, 8-29.

Carbonero Gamundí, M.A. y Caro Blanco, F. (2013). Huellas, principios y propuestas para el Sistema Público de Servicios Sociales en un contexto de crisis. Documentación Social $n .^{\circ} 170.121-142$.

Casado, D. y Fantova, F. (2007). Perfeccionamiento de los Servicios Sociales en España. Fundación FOESSA. Madrid

DOMÉNECH PASTOR, M. y GARCía RocA, J. (1990). Presentación y desarrollo de la ley. Revista de Servicios Sociales. Generalitat Valenciana, València.

FEMP. Informe sobre Las competencias de los Ayuntamientos en materia de Servicios Sociales tras la entrada en vigor de la Ley 27/2013 de la LRSAL. En http:// www.femp.es/files/3580-836-fichero/LAS\%20COMPETENCIAS\%20EN\%20 MATERIA\%20DE\%20SERVICIOS\%20SOCIALES\%20TRAS\%20LA\%20 ENTRADA\%20EN\%20VIGOR\%20DE\%20LA\%20LRSAL.pdf (consultado el 16/6/2014).

García Herrero, G. (coord.). (2007). Las nuevas Leyes de Servicios Sociales. Criterios para valorar su elaboración o sus contenidos. Asociación de Gerentes y Directoras de Servicios Sociales. Madrid. En http://www.directoressociales.com/images/LAS\%20NUEVAS\%20LEYES\%20DE\%20SERVICIOS\%20 SOCIALES.pdf (consultado el 4/9/2014).

Índice DEC 2013. Asociación de Gerentes y Directoras de Servicios Sociales En: http://www.directoressociales.com/images/documentos/idec\%2007.06.2013. pdf (consultado 1/9/2014). 
Informe de Rentas Mínimas de Inserción (2011). M. ${ }^{\circ}$ Sanidad, Servicios Sociales e Igualdad. En http://www.eapn.es/ARCHIVO/documentos/recursos/5/ InformeRMI2011.pdf (Consultado el 16/1/2014).

Informe del Ayuntamiento de Zaragoza sobre la aplicación de la LRSAL. En http:// www.zaragoza.es/cont/paginas/noticias/rsal.pdf (Consultado el 16/6/2014).

Informe del Ayuntamiento de Valencia sobre la aplicación de la LRSAL (reservado).

Mira-Perceval, M.T., De Alfonseti, N. y Giménez Bertomeu. V.M. (2007). Servicios Sociales. Estructura, dinámica, políticas y estrategias en España y la Comunidad Valenciana. Universidad de Alicante.

SAntos Martí. J. (2012). El cuarto Pilar. Un nuevo relato para los Servicios Sociales. Paraninfo. Madrid.

UCEDA I MAZA, F.X. (2011). Los Servicios Sociales en España: desarrollo y articulación en los nuevos escenarios. Documentación Social n. ${ }^{\circ}$ 162. 235-258.

Uceda i Maza, F.X., Pitarch Garrido, M.D., Pérez-Cosín, J.V. y Rosaleny CASTEll, R. (2012). La evolución de la estructura básica de los Servicios Sociales en la Comunitat Valenciana. Treinta años en el área metropolitana de Valencia. Revista Arxius, n. $^{\circ}$ 27. 83-100.

Vilà MANCEBO, A. (2012). La nueva generación de leyes autonómicas de servicios sociales (2006-2011): análisis comparativo. Revista Azarbe. n. ${ }^{\circ} 1.143-155$.

\section{Legislación}

Ley 5/2009, de 30 de junio, de Servicios Sociales de Aragón

DECRETO 143/2011, de 14 de junio, del Gobierno de Aragón, por el que se aprueba el Catálogo de Servicios Sociales de la Comunidad Autónoma de Aragón

I Plan estratégico de Ss.Ss de Aragón 2012-15

Árbol de prestaciones del Catálogo de Ss.Ss

DECRETO LEGISLATIVO 1/2006, de 27 de diciembre, del Gobierno de Aragón, Ley de Comarcalización de Aragón.

Ley de Cantabria 2/2007, de 27 de Marzo, de Derechos y Servicios Sociales. Orden EMP/51/2009, de 15 de mayo, por la que se establece el Mapa de Servicios Sociales de Cantabria.

BOC n. ${ }^{\circ} 136$ de 16/7/2009, Resolución aprobando el Plan Estratégico de Servicios Sociales 2008-2011 de la Comunidad Autónoma de Cantabria

Decreto $17 / 1989$, de 7 de abril, por el que se regula la organización y régimen de funcionamiento de los Servicios Sociales Comunitarios en Cantabria 
Ley de Cantabria 3/2009, de 27 de noviembre, de creación del Instituto Cántabro de Servicios Sociales

Ley 16/2010, de 20 de diciembre, de servicios sociales de Castilla y León Decreto 56/2005, aprobación del Plan estratégico de sistema de acción social de Castilla y León

Algunos planes estratégicos provinciales: León, Soria, Salamanca

Ley 14/2010, de 16 de diciembre, de servicios sociales de Castilla-La Mancha Decreto 181/2009, de 01/12/2009, sobre los convenios de colaboración con las Entidades Locales para el desarrollo de las Prestaciones Sociales Básicas de la Red Pública de Servicios Sociales

Decreto 287/2004, de 28 de diciembre, por el que se regula la estructura territorial de las Zonas y Áreas de Servicios Sociales y la estructura funcional del Sistema Público de Servicios Sociales de Castilla-La Mancha

Orden de 30-04-2008, de la Consejería de Bienestar Social, por la que se establecen las bases reguladoras y la convocatoria de subvenciones en el ámbito del Programa Regional de Acción Social, para la financiación de las Prestaciones Sociales Básicas de la Red Pública de Servicios Sociales en Castilla-La Mancha

Ley 13/2008, de 3 de diciembre, de servicios sociales de Galicia

Decreto 99/2012, de 16 de marzo, por el que se regulan los servicios sociales comunitarios y su financiación

Decreto 40/2014, de 20 de marzo, por el que se crea la Agencia Gallega de Servicios Sociales y se aprueban sus estatutos

Ley 4/2009, Servicios Sociales de las Illes Balears

Ley 4/1999de Inspección en materia de Ser.Soc

Ley 14/2001, de 29 de octubre, de atribución de competencias a los Consejos Insulares en materia de Servicios Sociales y Seguridad Social.

Decreto 48/2011, de 13 de mayo por el que se regulan los principios generales y las directrices de coordinación de los servicios sociales comunitarios básicos Decret 56/2011, Cartera Bàsica de Serveis Socials de les Illes Balears 2011-2014 Ordre de la consellera d'Afers Socials, de 8 de febrer de 2011 per la qual s'estableix el catàleg de serveis socials d'àmbit suprainsular de les Illes Balears Análisis del Plan de Prestaciones Básicas 2011. 
Decreto 66/1999, Reglamento Regulador del Sistema Balear de Servicios Sociales

Decreto 62/2010, la composición, el funcionamiento y las atribuciones del Comité de Ética de Servicios Sociales

Decreto 61/2010, la composición, la organización y el funcionamiento del Consejo de Servicios Sociales de las Illes Balears

Decret 97/2009, Consell de Coordinació de Benestar Social de les Illes Balears Plan estratégico de Mallorca 2010/13

Ley 7/2009, de 22 de diciembre, de Servicios Sociales de La Rioja Ley 3/2007, de 1 de marzo, de Calidad de los Servicios Sociales

Decreto 51/2010, de 12 de noviembre, por el que se regula el Consejo Riojano de Servicios Sociales

Decreto 31/2011, de 29 de abril, por el que se aprueba la Cartera de servicios y prestaciones del Sistema Público Riojano de Servicios Sociales

Memoria 2012. Dirección General de Servicios Sociales

Ley Foral 15/2006, de 14 de diciembre, de Servicios Sociales de Navarra

Decreto foral 33/2010 de la zonificación de Ser. Soc de Navarra

Decreto foral 32/2013 reglamento desarrollo de Programas y Financiación de los Servicios Sociales de Base. Tramo fijo

Orden foral 618/2013 se aprueba forma de medir el tramo variable de financiación de los Ser. Soc

Decreto foral 69/2008, cartera de Servicios Sociales y Cartera actualizada a 2012 (hoja interactiva de la web

Orden foral 260/2010, plan de Calidad Ss.Ss 2010-13

Documento base para Plan atención Comunitaria de los Servicios Sociales de Base

Plan estratégico Ser. Soc 2008-12

Ley 12/2008, de 5 de diciembre, de Servicios Sociales de Euskadi

Decreto 64/2004, de 6 de abril, Carta de derechos y obligaciones de usuarios y profesionales de los Ss. Ss en Euskadi.

Ley 10/2000, de 27 de diciembre, de Carta de Derechos Sociales.

Plan estratégico de Ser. Soc. de Euskadi 2011/14

Decreto 124/2006, de 13 de junio, del Consejo Vasco de Bienestar Social 
Mapa y Memoria económica de Ser. Soc. de Euskadi 2012

II Informe Consejo Vasco Ser. Soc. 2012.

Informe del Ararteko sobre los Ser. Soc. 2010

Ley 12/2007, de 11 de octubre, de Servicios Sociales, de Catalunya.

Ley 13/2006, de prestacions socials de caràcter econòmic

Decreto 202/2009, dels òrgans de participació i de coordinació del Sistema Català de Serveis Socials

Recomendaciones para la creación de los Consejos Territoriales y Locales

Decreto 142/2010, s'aprova la Cartera de Serveis Socials 2010-2011.(aún en vigor)

Orden ASC/349/2010, de 16 de juny, del Comitè d'Ètica dels Serveis Socials de Catalunya.

Plan Estratégico 2010/13

Plan Calidad 2010/13

El estado de los Ser. Soc. en Catalunya 2010/13

Ley 5/1997, Sistema de Servicios Sociales Comunidad Valenciana

Orden de 9 de abril de 1990, de la Consellería de Treball i Seguretat Social (explicación de programas Ss.Ss. generales y recursos especializados)

Decreto 90/2002, control de la calidad de los centros y servicios de acción social y entidades evaluadoras de la misma, en la Comunidad Valenciana

Ley 4/2012, Carta de Derechos Sociales de la Comunitat Valenciana. 